\title{
Potencialidad de Puerto Deseado y Camarones (Argentina) como destinos de cruceros a partir de sus competencias territoriales
}

\author{
Potentiality of Puerto Deseado and Camarones (Argentina) as cruise destinations from their \\ territorial competences
}

\author{
Historial del artículo \\ Recibido: \\ 26 de mayo de 2020 \\ Revisado \\ 19 de octubre de 2020 \\ Aceptado:
}

03 de noviembre de 2020

\author{
Carolina Cohen ${ }^{\mathrm{a}}$, Marisol Vereda ${ }^{\mathrm{b}}$ y Graciela Benseny ${ }^{\mathrm{c}}$ \\ a Universidad Nacional de Tierra del Fuego, Antártida e Islas del Atlántico Sur, Ushuaia, Argentina. Beca Postdoctoral CONICET. \\ Correo electrónico: ccohen@untdf.edu.ar \\ b Universidad Nacional de Tierra del Fuego, Antártida e Islas del Atlántico Sur, Ushuaia, Argentina. \\ c Universidad Nacional de Mar del Plata, Mar del Plata, Argentina.
}

\section{Palabras clave}

Competitividad, Patagonia argentina, Puerto Deseado y Camarones, turismo de cruceros

\section{Keywords}

Competitiveness, cruise tourism, Patagonia argentina, Puerto Deseado and Camarones

\section{Resumen}

El turismo de cruceros está comúnmente asociado a una práctica exógenamente determinada. Sin embargo, como práctica social, se emplaza en un espacio cargado de connotaciones sociales y culturales; haciendo uso de un territorio construido socialmente. Desde esta mirada la decisión de optar por este tipo de actividad es tomada teniendo en cuenta un conjunto de elementos que va más allá de las características del buque. Los territorios en cuestión deben poseer una serie de condiciones que resulten favorables para su competitividad, fundamentalmente asociadas a la presencia de recursos naturales y culturales que conforman la oferta de sitios potenciales de visita y la prestación de servicios. Estos factores forman parte de las competencias territoriales que poseen los destinos y pueden actuar como elementos que favorezcan y potencien su inserción en el turismo de cruceros. Puerto Deseado y Camarones, dos puertos de la Patagonia argentina, han mostrado interés por esta actividad surgiendo el interrogante respecto a las competencias territoriales que poseen para el desarrollo del turismo de cruceros. El trabajo optó por un enfoque cualitativo, apoyado en técnicas cuantitativas desarrollado durante la temporada de verano 2017-2018 y consistió en el relevamiento y análisis de diferentes componentes territoriales complementado con la opinión de informantes clave. Los resultados obtenidos reflejan la potencialidad que poseen ambas localidades en términos de sitios de visita y planta turística destacándose que, si bien cuentan con un conjunto de componentes territoriales que los posicionarían competitivamente en el mercado de cruceros, también es necesario fortalecer otros.

\begin{abstract}
Cruise tourism is associated with an exogenous practice to the territory; however, it is in a space laden with social and cultural connotations. The decision to choose this type of activity is made considering a set of elements beyond the ship's characteristics. The territories concerned must have several conditions that are favorable to their competitiveness associated with the presence of natural and cultural resources that make up the provision of potential visitation sites and the provision of services. These factors are part of the territorial competences that the destinations possess and can act as elements to be inserted into cruise tourism. Puerto Deseado and Camarones, two ports of Patagonia argentina, have shown interest in this activity by raising the question of the territorial competences they have for the development of cruise tourism. The work opted for a qualitative approach supported by quantitative techniques developed during the season 2017/2018, consisted of survey and analysis of different territorial components complemented by the opinion of key informants. The results reflect the potential of both cities in terms of visitation sites and tourist plant. While they have a set of territorial components that would position them competitively, they also must be strengthened.
\end{abstract}




\section{Introducción}

Al plantear el turismo como una práctica socioespacial se reconocen las diversas manifestaciones turísticas que pueden originarse en el territorio cuya yuxtaposición, como aclaran Vera, López Palomeque, Marchena \& Antón (1997) pueden ser coincidentes o no, pero siempre exigen una organización espacial, un modelo de asentamiento multigenético, complejo, formal y funcional. Sin embargo, Callizo Soneiro (1991) sostiene que todo espacio que posea potencial turístico no necesariamente implica que llegue a serlo. Esto dependerá fundamentalmente del interés y capacidad de los componentes territoriales por llevarlo a cabo. Pensar el turismo desde la particularidad de ciertos ámbitos geográficos, pero a la vez, sin desconocer los procesos más amplios que lo intervienen, permiten abordarlo, como propone Troncoso (2008), desde la idea de lugar.

Este concepto es analizado por Agnew (1987, citado en Oslender, 2002) desde tres elementos que lo fundamentan: localidad, ubicación y sentido de lugar. El primero, representa no solo los escenarios físicos donde ocurre la interacción social, sino además las interacciones típicas que desarrolla; el segundo refiere al espacio geográfico concreto, el orden macroeconómico y político y, por último, el sentido de lugar, como la fuerza que modela las relaciones e interacciones sociales. En otras palabras, es el espacio inmediato del hombre, donde los procesos mentales originados y las reacciones correspondientes están determinados por las actitudes de las personas. Éste es el espacio vivido, reafirma Oslender (2002), dinámico, simbólico y saturado de significado; donde se desarrolla una relación dialéctica constante con las representaciones territoriales. Se estructura no solo por las prácticas propias que en él se generan sino por procesos sociales que ocurren a escalas más amplias.

A partir de entonces, un lugar turístico es más que el simple ámbito de interacción entre turistas y población local, implica un proceso de valoración del espacio a partir de una práctica social específica que dará lugar a una serie de actividades económicas (Troncoso, 2008). Para que este lugar pueda ser aprovechado como tal, requiere de la creación y/o acondicionamiento de infraestructura y equipamiento que haga posible su consumo. En otras palabras, no alcanza con despertar valor para los actores que intervienen en la práctica, sino que además es necesario un proceso de apropiación y aprovechamiento efectivo de sus componentes.

La movilidad que caracteriza al turismo de cruceros permite distinguirlo del resto de las modalidades turísticas, al brindarle la capacidad de diversificar las zonas de operación con gran flexibilidad. Como expresan Cohen, Vereda \& Benseny (2019) distintos factores influyen en la definición de los itinerarios turísticos, por ejemplo, la estacionalidad, el clima, los atractivos y la localización, son algunos de los elementos que las compañías de cruceros tratan de articular con el objeto de mantener operativos a los cruceros durante todo el año (Butler, 2008; Martínez, 2012). Por su parte, las empresas de cruceros han generado estrategias que permitieron la diversificación de este segmento, atrayendo pasajeros más jóvenes, ofreciendo variedad en el precio, duración e itinerarios, entre otros (Johnson, 2002).

Como parte de sus estrategias competitivas y debido al aumento constante tanto de la capacidad global de sus flotas como del tamaño de los cruceros, la incorporación de nuevos puertos-destino ha producido un salto cuantitativo en la llegada de cruceristas a diversos puertos (Jensen \& Daverio, 2004). En este sentido, se destacan territorios que despiertan interés para las compañías otorgándole a la perspectiva espacial un rol fundamental. Los mismos adquieren el carácter de regiones y si bien existe una gran diversidad de posturas en relación a este concepto, desde el turismo de cruceros es posible entenderlas en relación con una construcción intelectual que se genera a partir del objeto de estudio (Paasi, 1986). En otras palabras, se trata de una construcción mental que se materializa en el espacio geográfico a partir de la conjunción de elementos que lo distinguen y diferencian del resto.

Argentina, forma parte de la Región Secundaria y es el segundo destino de turismo de cruceros en Sudamérica, liderando la oferta los puertos de Buenos Aires y Ushuaia que, junto con Puerto Madryn y Puerto Argentino en las Islas Malvinas, completan la oferta disponible en los itinerarios sudamericanos, participando de las rutas que recorren el norte y sur de la región. Sin embargo, otros puertos han puesto el foco en la posibilidad de incluirse en la ruta de cruceros. Esta información es consistente con el estudio previamente realizado, el cual plantea la atractividad de los puertos de Camarones y Puerto Deseado para el desarrollo del turismo de cruceros a partir de la valoración asignada tanto por cruceristas como por los actores clave de las localidades de estudio (Cohen et al., 2019).

En este contexto, surge el interrogante: ¿cuáles son las competencias territoriales que poseen Puerto Deseado y Camarones para el desarrollo del turismo de cruceros? Es así que se plantea como objetivo conocer el posicionamiento de estos puertos y sus áreas de influencia para el desarrollo 
del turismo de cruceros, a partir de las capacidades territoriales que los caracterizan. Para el desarrollo del trabajo se optó por un enfoque cualitativo, apoyado en técnicas cuantitativas. El estudio consistió en el relevamiento y análisis de diferentes componentes territoriales y se complementó con la opinión sobre el tema provista por informantes claves. El período de recolección de datos se concentró en la temporada de verano 2017-2018 en las localidades objeto de estudio.

\section{Marco teórico}

El espacio es una construcción que resulta de la acción y relación social, es indudablemente producido y no puede explicarse únicamente por la naturaleza, como contexto dado, ni por su historia previa (Lefebvre, 2013). En palabras de Santos (1987), "no es una estructura de aceptación, de encuadramiento o cualquier otra cosa, sino una estructura social como las otras", citado por Silveira (2011, p.3). Como tal, la función que adopte dependerá fuertemente de la valoración social que se le asigne, para poder adquirir tantos significados como valoraciones represente.

Una práctica que finalmente ha sido aceptada como gran consumidora de espacio es la turística y su estudio desde esta perspectiva permite entenderla como un importante factor de transformación del espacio y su sociedad. El hecho turístico confiere una repercusión espacial importante porque para que el mismo se lleve a cabo requiere de una serie de articulaciones y manifestaciones territoriales que le permitan concretarlo. Se reconoce como una actividad dinámica con capacidad de redefinir al territorio, y así transformar, adecuar e integrar pueblos y regiones al sistema económico (Bertoncello, 2002; Vera et al., 1997; Wallingre, 2017, entre otros).

De esta manera, se plantea la actividad turística desde la integralidad y la mirada sistémica. "La proposición sistémica radica en la interacción horizontal mediante la negociación y cooperación de los actores y la integración vertical mediante la participación en las redes de articulación dimensional" (Mantero, 1999, p. 75). Se trata de pensar al turismo como un fenómeno capaz de generar desarrollo hacia el interior de cada sociedad, considerando las oportunidades que brinda el contexto. No se limita solo al mejor aprovechamiento de los recursos que posee un territorio, sino construir una estrategia que permita endogeneizar los efectos favorables derivados de la actividad turística (Vereda \& Jensen, 2014).

El turismo así pensado requiere de la articulación e interacción de los factores de desarrollo que propone
Boisier (1997). La identificación de estos factores (los actores, las instituciones, la cultura, los procedimientos, los recursos y el entorno) contribuyen a reconocer cómo funciona esa sociedad y quiénes intervienen en el desarrollo de un territorio organizado (Vereda \& Jensen, 2014). Pero la simple enumeración o presencia de estos no asegura que el desarrollo se produzca, este hexágono debe ser construido, potenciado y direccionado. En este marco, las ventajas comparativas y competitivas adquieren un rol fundamental,

las ventajas comparativas son las que dan origen al nacimiento y expansión de los destinos turísticos, especialmente en relación a los recursos naturales y culturales. Luego, son las ventajas competitivas las que generan un valor añadido al destino y hacen posible un posicionamiento destacado en relación a la calidad de los servicios, la imagen y el cuidado del medio ambiente. (Sancho, 1998 citado en Varisco, 2008, p. 104)

El concepto de competitividad llevado a la práctica no solo permite optimizar los procesos productivos e incrementar las habilidades laborales; también, constituye una herramienta de gestión territorial en el sentido que son los propios lugares los que tienen la capacidad de promover su desarrollo, al establecerse como entornos altamente favorables para atraer actividades económicoproductivas (Ruiz-Velazco Castañeda, 2015).

El desarrollo territorial mucho depende de las capacidades y habilidades que la población local es capaz de traducir en términos productivos (...), establecer estrategias que los fortalezcan y orienten hacia un plano que tienda a mejorar las condiciones de competitividad (p. 56).

En este sentido, pensar al turismo como un proceso que puede desencadenar el desarrollo en el territorio, implica realizar un gran esfuerzo de planificación, coordinación, cooperación y gestión, atendiendo a la percepción de los residentes sobre las implicancias del turismo de cruceros en el destino (Brida, Riaño, Such-Devesa \& ZapataAguirre, 2012; Brida, Riaño \& Zapata-Aguirre, 2012; Harrill, 2004).

El turismo de cruceros, como práctica social, se produce en un entorno de constante competencia. Es un segmento que ha adquirido un intenso dinamismo en los últimos años, Butler (2008) desde la Organización Mundial del Turismo (OMT) afirma que, desde hace tiempo se asiste a un rápido proceso de crecimiento de pasajeros, permitiendo 
la creación, diversificación y consolidación de destinos, así como la potenciación de otros. El arribo de cruceros a una localidad portuaria siempre ha generado grandes expectativas en relación a las posibilidades económicas y financieras que ofrece (Brida, Bukstein, Garrido, Tealde \& Zapata-Aguirre, 2010; Losano \& Tagliorette, 2012). Sin embargo, la percepción que hoy se tiene sobre el turismo ha llevado a pedirle que demuestre algo más que su eficacia económica centrándose también en los aspectos ambientales y sociales (Crouch \& Ritchie, 1999).

En el destino turístico se encuentran todos los factores que a partir de su articulación generan ventajas competitivas (Monfort Mir, 1999). La importancia radica en cómo se relacionan y se ponen en marcha "porque (...) la verdadera capacidad de un destino turístico para competir también implica de sus fortalezas sociales, culturales, políticas, tecnológicas y ambientales" (Ritchie \& Crouch, 2003, p. 2). Proponer al turismo de cruceros como una actividad factible de generar desarrollo, implica pensarlo como un proceso complejo pluridimensional. Se entiende, entonces que el arribo de cruceros a un puerto pone de manifiesto un encadenamiento de elementos que involucran la acción concertada de todos ellos. "No se trata solamente de crecimiento y acumulación sino de una mejor distribución de la producción, de una transformación y mejoramiento del territorio en general, propiciando un mejoramiento armónico de los ejes que le dan sentido" (Vereda, 2007, p. 2).

Desde esta mirada, se lo propone como un segmento de la práctica turística que presupone la compleja tarea de coordinar entre todos los factores que intervienen en el desarrollo considerando, como plantea Boisier (1997), que si la misma no se da de forma adecuada genera como resultado un aumento de la entropía en vez de incrementar la sinergia. Requiere de una articulación densa, inteligente y direccionada si se pretende proponerlo como una actividad generadora de desarrollo. Así se retoman y repiensan los factores desde la mirada del turismo de cruceros y se destaca la importancia de abordarlo desde la participación concertada de los diferentes actores que intervienen para gestionar los recursos propios del territorio, como así también, para aprovechar las externalidades que conlleva esta actividad.

Los actores por sí solos no poseen la fuerza suficiente para poder posicionar al puerto y su hinterland como destino de cruceros competitivo y con capacidad de desarrollo, es necesario que tengan la habilidad de dar respuesta a los cambios que este segmento conlleva. No se trata de construir más productos, sino que los ofrecidos sean únicos, novedosos y de calidad, "ofrecer vivencias únicas que sólo puedan ser experimentadas en el lugar en el que se crearon, de modo que haya que ir allí para consumirlas; y que estas experiencias se reinventen continuamente" (Ávila Bercial \& Barrado Timón, 2005, p. 30). La incorporación del territorio al imaginario turístico colectivo requiere la identificación de ciertos recursos y poder aprovecharlos para este fin, estos se refieren tanto a los materiales como a los inmateriales, pensando a los mismos como "aquel medio que permite utilizar su capacidad de referente histórico o natural, su potencial de ser interpretado de acuerdo a temáticas adecuadas y capaz de recibir un aprovechamiento racional que permita formar parte de un proyecto territorial" (Hernández \& Martín, 2002 citados en Vereda, 2008, p. 203).

Al plantearse la vinculación de los factores desde el turismo de cruceros se acuerda con Ávila Bercial \& Barrado Timón (2005) quienes afirman que:

el turismo no es un motor de desarrollo aislado, sino más bien un sector que se apoya en el marco general de desarrollo de un territorio y una sociedad, para integrar y aprovechar oportunidades, estructuras y recursos desde los que construir nuevas realidades productivas. (p. 33)

Competitividad y desarrollo se piensan como un binomio que a través de un marco de innovación y creatividad buscan promover mejoras en la calidad de vida de su población. Se propone una como un elemento de la otra y viceversa, como enlace conector entre el entorno global y el desarrollo local (Berumen, 2006).

Desde este marco proponer a los puertos y su hinterland como destinos de cruceros requiere de la articulación y relación de los diferentes factores que intervienen en el territorio, pensando a las mismas como herramientas que permitan dotarlos de ventajas competitivas que los distingan y posicionen en el mercado internacional. Al turismo como una práctica compleja y participativa no le basta contar con recursos para ser contemplados, requiere de productos que permitan adentrarse al territorio (Ávila Bercial \& Barrado Timón, 2005). Para ello se debe fomentar el desarrollo a partir de estrategias competitivas que permitan distinguirse del segmento y tener un posicionamiento especial para atender a las necesidades de la demanda. Las ventajas competitivas pueden ser creadas a través de las competencias básicas como las capacidades existentes de la comunidad receptora, que resultan únicas en atraer a visitantes (Alcerreca Molina \& Salazar Estrada, 2014) y de la articulación de distintos actores (Garay Tamajón \& Cànoves Valiente, 2012). 


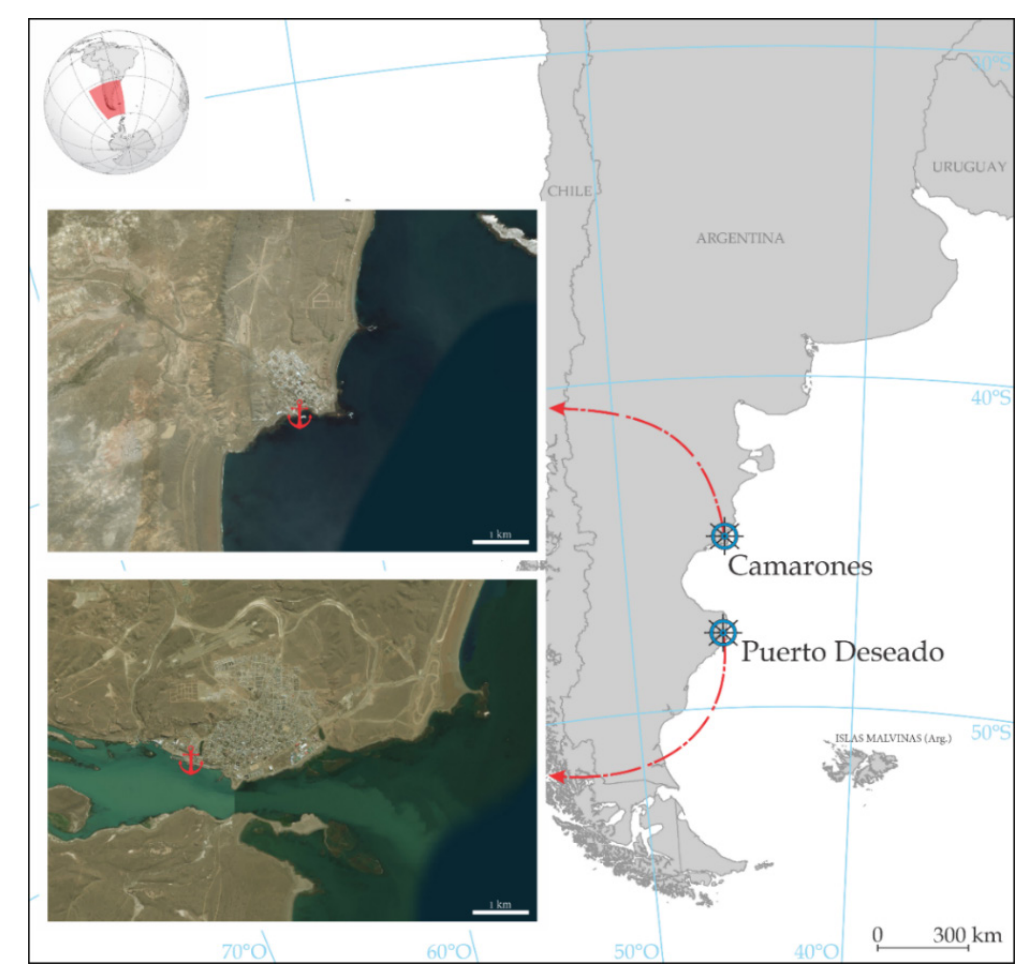

Figura 1. Localización de Puerto Deseado (Santa Cruz) y Camarones (Chubut). Fuente: Elaboración propia con base en QGis 3.4.0.

\section{Materiales y Métodos}

La Patagonia es comúnmente asociada a un espacio geográfico con diferentes niveles jerárquicos de organización y con una falta de contigüidad espacial (Roccatagliata, 2008). Sin embargo, está en sus particularidades territoriales las posibilidades de incentivar y afianzar la complementariedad y articulación. En relación con el turismo de cruceros, al actual corredor turístico que domina la Patagonia argentina (concentrado en los puertos de Puerto Madryn, Ushuaia y Puerto Argentino), se le podría incorporar una propuesta que permita vertebrar nuevas localidades costeras con jerarquía suficiente para motivar flujos de demanda turística nacional y/o internacional. "La dinámica y corta distancia entre atractivos y servicios resulta en una natural complementariedad que normalmente trasciende las barreras jurisdiccionales municipales, provinciales y regionales" (MINTUR, 2016, p. 141).

Desde esta perspectiva, Puerto Deseado y Camarones se proponen como espacios con potencialidad para incorporarse a la actividad. Se trata de dos localidades de la costa atlántica patagónica localizadas en las provincias de Santa Cruz y Chubut, respectivamente. Su principal actividad económica responde al sector primario y al empleo público; sin embargo, desde hace tiempo ha surgido el interés en la potencialidad de sus puertos para el desarrollo de turismo de cruceros (Cohen et al., 2019). Puerto Deseado, localizado en la provincia de Santa Cruz, se posiciona en los márgenes de la Ría Deseado $\left(47^{\circ} 45^{\prime} \mathrm{S}\right.$ y $\left.65^{\circ} 51^{\prime} \mathrm{O}\right)$, cuenta con 14.183 habitantes ${ }^{1}$. Camarones, por su parte, se ubica al sureste de la provincia de Chubut $\left(44^{\circ} 47^{\prime}\right.$ $S$ y $65^{\circ} 42^{\prime}$ O) y es ciudad cabecera del Departamento Florentino Ameghino contando con 1.296 habitantes $^{2}$ (figura 1).

Ambas localidades forman parte de la ecorregión estepa patagónica y la categorización de Kottek, Grieser, Beck, Rudolf \& Rubel (2006) las ubica en la clasificación climática del tipo frío árido estepario, pero puede oscilar entre templado y frío moderado. Se caracteriza por precipitaciones anuales escasas, no supera los $250 \mathrm{~mm}$

${ }^{1}$ Según Censo Nacional de Población, Viviendas y Hogares de la República Argentina (2010).

${ }^{2}$ Según Censo Nacional de Población, Viviendas y Hogares de la República Argentina (2010). 
y con una temperatura media anual que se ubica por debajo de los $18^{\circ} \mathrm{C}$. La cordillera de los Andes juega un rol fundamental en la composición climática (Coronato, Mazzoni, Vázquez \& Coronato, 2017; Morello, Matteucci, Rodriguez \& Silva, 2012; Schlüter, 1996), al atrapar en su ladera occidental a los vientos húmedos del Pacífico Sur, origina la aridez que caracteriza a toda la región. La costa patagónica refleja un margen pasivo con una extensa plataforma continental; al norte se caracteriza por extensas playas de arena formadas de sedimentos terrígenos y biogénicos. El sur se encuentra asociado a sedimentos terciarios y cuaternarios, caracterizado en general, por costas erosivas y con acantilados activos (Gil et al., 2019)

Aunque la Patagonia sea visualizada como una unidad regional, presenta heterogeneidad en sus paisajes y en sus procesos históricos. En general, se distinguen dos zonas bien definidas denominadas Patagonia occidental y oriental en función de su ubicación, al oeste o al este de la cordillera de los Andes (Bandieri, 2005). Tanto en Puerto Deseado como en Camarones, las costas que las envuelven, caracterizadas por cabos y bahías, ofrecen un ambiente propicio para el hábitat de una gran variedad de fauna marina. Cabe destacar que se trata de un espacio con escasa intervención humana, generando una gran atractividad para el turismo (Cohen et al., 2019). Además, las líneas de crucero ofrecen un aumento de itinerarios a destinos remotos para satisfacer una demanda creciente con interés por turismo de naturaleza (Cerveny, Miller \& Gende, 2020).

El estudio consistió en el reconocimiento de los puertos y sus áreas de influencia a través del relevamiento de la oferta de sitios de visita, para conocer y recorrer en el marco del turismo de cruceros, y la prestación de servicios, tanto para los visitantes como para los buques. Para ello, se llevó a cabo una identificación in situ de los sitios de visita, así como también de la planta turística, durante la temporada de verano 2017-2018. Esta información fue complementada con fotografías, material brindado por los entes públicos de turismo de los puertos objeto de estudio, imágenes disponibles en Google Earth y el análisis de contenido de páginas web de empresas de turismo receptivas y de los organismos públicos.

Para la elaboración de la ficha de relevamiento correspondiente a los sitios de visita se tomó como base la metodología propuesta por Varisco et al. (2014), quienes plantean un análisis desde tres características fundamentales: a) Atractividad: aborda los indicadores que permiten profundizar sobre las particularidades de los atractivos que integran a los sitios de vista. Corresponden a: diversidad de los atractivos que integran los sitios de visita; singularidad y autenticidad; grado de preservación que reviste.

b) Aptitud: se basa en indicadores que visualizan las condiciones en las cuales se encuentran los atractivos para ser visitados. Incluyó: tipos de turismo; duración de la visita; tipo de comunicación; incorporación en excursiones regulares.

c) Accesibilidad: refiere a indicadores que permiten indagar respecto a las características de acceso que revisten los sitios de visita. Se consideró: condición de acceso; tipo de transporte; distancia desde el puerto; estacionalidad.

Una vez pautados los pasos para el reconocimiento de los sitios de visita, se elaboró un listado de estos con base en la información obtenida, alcanzando un total de veinticinco sitios de visita (diecisiete correspondientes a Puerto Deseado y ocho a Camarones). El registro se volcó en una matriz de datos y se procedió a su análisis. El mismo se complementó con la producción de cartografía temática generada a partir del software libre QGis 3.4.0. En su elaboración se tuvo en cuenta que algunos sitios de visita incluyen un conjunto de atractivos que se distribuyen en el espacio, en esos casos se consideró un punto de referencia para la generación de cartografía. Así mismo, para que los sitios de visita puedan ser representados con claridad, facilitando su lectura y análisis, los puertos fueron cartografiados diferenciándose en secciones determinadas en función a la disposición espacial de los sitios de visita. Se generaron cuatro secciones para Puerto Deseado y tres para Camarones (figura 2).

Respecto a la prestación de servicios, el relevamiento se concentró en dos ítems, equipamiento e infraestructura, para ser en ambos casos contextualizados en el turismo de cruceros. En relación a la infraestructura, se profundizó sobre las características que revisten los puertos objeto de estudio.

El reconocimiento de los puertos y sus áreas de influencia se complementó con entrevistas en profundidad para conocer la opinión de informantes calificados en el tema pertenecientes a los organismos públicos nacionales $(\mathrm{ON})$, provinciales $(\mathrm{OP})$, municipales $(\mathrm{OM})$ y empresas privadas correspondientes a prestadores de servicios marítimos (PSM) y turísticos (PST). Se realizaron un total de quince entrevistas durante la temporada de verano 


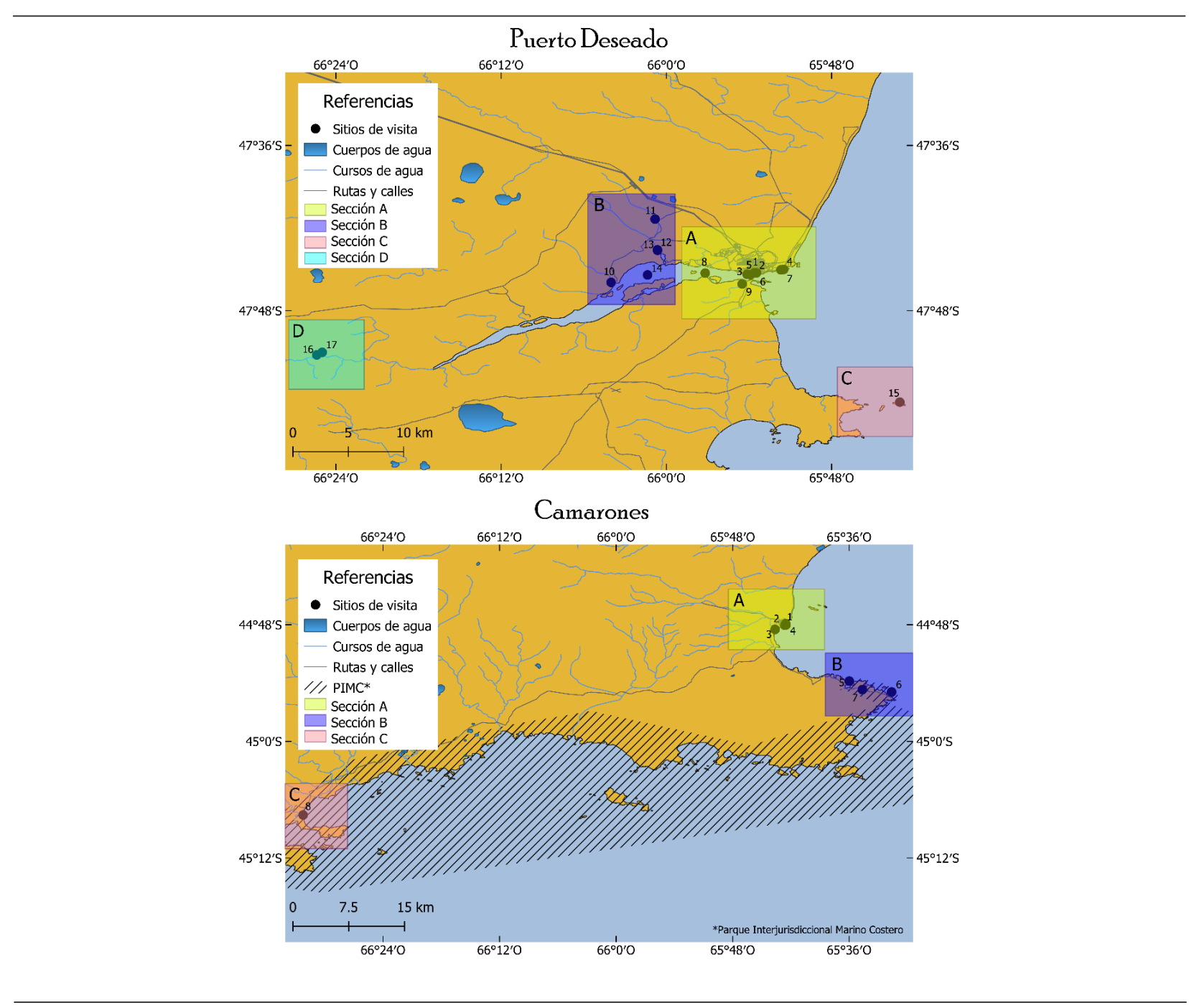

Figura 2. Distribución de los sitios de visita en cada localidad según secciones de referencia. Fuente: Elaboración propia con base en QGis 3.4.0.

2017-2018 y a partir de ellas se generaron categorías y códigos para agrupar la información y analizarla a la luz de los relevamientos realizados.

\section{Resultados}

\section{Potencialidad de los sitios de visita}

El primer análisis de los sitios de visita que poseen las localidades se concentró en la atractividad que revisten. Acorde a las características propias de cada una de las localidades seleccionadas, ambas proponen una interesante cantidad y diversidad de sitios de visita asociados a diferentes componentes del paisaje, la posibilidad de conjugar en una misma área una variedad de ofertas vinculadas a recorrer y conocer el destino que potencian su atractividad. Entre las ventajas que estos sitios reflejan se destaca el conjunto patrimonial y cultural que los caracteriza (tabla 1).

La presencia de los componentes del paisaje como factores positivos para la activación de la práctica turística no es menor cuando se proponen como un atributo diferencial de los lugares que concentran y representan unos valores y una visión del mundo y contribuyen a la creación de destinos mediante acciones de interés y de relaciones sociales que se activan a múltiples escalas territoriales (Bertoncello, 2010; Prats, 2005).

Esta característica es también planteada como una de las fortalezas destacadas por los entrevistados. La valoración responde en gran parte al imaginario social que representan los recursos naturales y culturales. Esto es consecuencia de 
Tabla 1

Diversidad de los sitios de visita.

\begin{tabular}{|c|c|c|c|}
\hline & Sitios de Visita & Componentes que lo conforman & Diversidad \\
\hline & \multicolumn{3}{|l|}{ Puerto Deseado } \\
\hline 1 & Museo del Pueblo & Historia local. & Cultural \\
\hline 2 & Museo Ferroviario & Historia del ramal ferroviario de Puerto Deseado y del país. & Cultural \\
\hline 3 & Circuito "De cara a la Livertá" & Circuito histórico que revive los eventos sucedidos durante las huelgas obreras de 1921 y 1922. & Cultural \\
\hline 4 & Circuito "Derrotero del Corsario" & $\begin{array}{l}\text { Circuito histórico que refleja la historia del navegante inglés Thomas Cavendish, quien visitó } \\
\text { Puerto Deseado en } 1586 .\end{array}$ & Cultural \\
\hline 5 & Museo Municipal Mario Brozoski & Historia y arqueología de la localidad. & Cultural \\
\hline 6 & Museo Policlínico & Historia y arquitectura local. & Cultural \\
\hline 7 & Cuevas de los Leones & $\begin{array}{l}\text { Roca Leones, Cueva del Indio, Cuevas Chicas, Cueva de los Leones, Las piletas, Punta } \\
\text { Cavendish. }\end{array}$ & Natural \\
\hline 8 & Ría Deseado & Ría Deseado, Isla Chaffers, avifauna, Isla Larga, fauna marina, Isla de los Pájaros. & Natural \\
\hline 9 & Piedra Toba & Puerto Jenkins, Isla Chaffers, Piedra Toba, Avifauna, fauna marina & Mixto \\
\hline 10 & Cerro Van Noort & Bahía Uruguay, Cañadón del Puerto, Isla del Rey, Cerro Van Noort, avifauna, fauna marina. & Mixto \\
\hline 11 & Gruta de Lourdes & Santuario, Cañadón de las Bandurrias, macizo de rocas volcánicas. & Cultural \\
\hline 12 & Camino Costero & $\begin{array}{l}\text { Cañadón del Puerto, Cañadón del Indio, Cañadón Giménez, Cañadón Paraguayo, Cañadón } \\
\text { Torcido. }\end{array}$ & Natural \\
\hline 13 & Cañadón del puerto & $\begin{array}{l}\text { Ría Deseado, Isla Chaffers, Barrancas de los Cormoranes, Isla Larga, Isla de los Pájaros, } \\
\text { Cañadón del Puerto, Fragata Swift. }\end{array}$ & Natural \\
\hline 14 & Hoorn & $\begin{array}{l}\text { Cañadón del Puerto, Bahía Magallanes, Bahía Uruguay, sitio histórico Hoorn, avifauna, fauna } \\
\text { marina. }\end{array}$ & Mixto \\
\hline 15 & Isla Pingüino & Isla Pingüino, Faro antiguo, Factoría lobera, avifauna, fauna marina. & Mixto \\
\hline 16 & Derrotero Darwin & Cañadón del Puerto, sitio histórico Hoorn, Bahía Concordia, Derrotero de Darwin. & Mixto \\
\hline \multirow[t]{2}{*}{17} & Campamento de Darwin & Estancia Aurora, Paso Marsicano, Miradores de Darwin. & Mixto \\
\hline & \multicolumn{3}{|l|}{ Camarones } \\
\hline 1 & $\begin{array}{l}\text { Museo Provincial "Familia de } \\
\text { Perón" }\end{array}$ & Historia del líder político y social en su niñez junto a su familia y su paso por la Patagonia. & Cultural \\
\hline 2 & Circuito Histórico Pedestre & $\begin{array}{l}\text { Recorrido cultural, histórico y arquitectónico a través de antiguas edificaciones y monumentos } \\
\text { por el ejido urbano. }\end{array}$ & Cultural \\
\hline 3 & $\begin{array}{l}\text { Sendero de interpretación } \\
\text { ambiental }\end{array}$ & Playa El Arroyo, Marisma, estepa, mar & Natural \\
\hline 4 & Museo "El rincón de la historia" & $\begin{array}{l}\text { Muestra arqueológica y fósil, "La casita del telégrafo". Productividad de Camarones en sus } \\
\text { comienzos y en la actualidad. }\end{array}$ & Cultural \\
\hline 5 & Caleta Sara & Caleta, mar, flora, avifauna, fauna marina y terrestre. & Natural \\
\hline 6 & $\begin{array}{l}\text { Parque Interjurisdiccional } \\
\text { Marino Costero Patagonia } \\
\text { Austral }\end{array}$ & $\begin{array}{l}\text { Isla Moreno, Isla Sola, Isla Arce, Isla Leones, Isla Rasa, Isla Larga, Isla Tovita, Isla Tova, Isla } \\
\text { Lobos, Isla Pequeño Robledo, Isla Gran Robledo, Isla Ceballos, Isla Viana, Isla Vernaci, Isla } \\
\text { Quintano, Bahía Bustamante, avifauna, fauna marina. }\end{array}$ & Natural \\
\hline 7 & Pingüinera - Cabo dos Bahías & Cabo dos Bahías, Caleta Sara, Cerro dos Bahías, avifauna, fauna marina y terrestre. & Natural \\
\hline 8 & Bahía Bustamante & $\begin{array}{l}\text { Playa de los Toboganes, Playa del Amor, Playa de las Roquitas, Caleta Malaespina, Isla } \\
\text { Pingüino, Isla Vernaci, Isla Viana Cabo Aristizábal, Bahía San Jorge, avifauna, fauna marina y } \\
\text { terrestre, historia local, sitios arqueológicos. }\end{array}$ & Mixto \\
\hline
\end{tabular}

Fuente: Elaboración propia. 
la posmodernidad, dirigida por las fuerzas de globalización, que desdibujan los límites entre culturas y concibe a la era de la simulación (Cohen, 2005), la búsqueda de lo auténtico y único entre los elementos que componen al espacio geográfico resurge con un recargado significado social. Es lo que les permite distinguirse del resto, es así como el "turismo como fenómeno contemporáneo, que involucra al conjunto de la sociedad significa la búsqueda permanente de lo exótico (...) mostrar, de proponer y proponerse como objeto diferenciado" (Bustos Cara, 2001, p. 6).

El producto natural e histórico que nosotros tenemos, yo creo que muy pocas ciudades en la Patagonia lo tienen (...) acá está el campamento de Darwin, está intacto (...) fue un peregrinar de exploradores y aventureros de todo el mundo. (OP-4, Puerto Deseado, 1 de marzo de 2018)

Sumado a la diversidad que ofrecen, los puertos poseen otra ventaja que les permitiría potenciar aún más el desarrollo de esta actividad; la presencia de sitios de visita que revisten de singularidad y atractividad, en relación con los otros puertos de cruceros de la Patagonia y de la región. Puerto Deseado, con sus visitas por la Ría y por el Cañadón del Puerto, ofrece la oportunidad de avistar al Cormorán Gris (Phalacrocorax gaimardi) cuyas colonias se localizan, en Argentina, solo en la provincia de Santa Cruz, con un total de trece colonias de nidificación y una población estimada en 900-1100 parejas reproductivas (Frere, Quintana \& Gandini, 2005). Además, adentrándose a la Ría es posible replicar la ruta realizada por el explorador Charles Darwin en 1833 y llegar hasta el punto exacto donde el mismo estableció su campamento. Por su parte, Bahía Bustamante ubicada en las cercanías de Camarones fue considerada por el New York Times ${ }^{3}$ como "La Galápagos argentina", para otorgar la oportunidad de visitar y recorrer un espacio cargado de naturaleza prístina o escasamente alterada. Sobre este lugar, un representante del sector turístico opina lo siguiente:

Bustamante tiene un buen equilibrio, tiene una historia que es rica, tiene flora y fauna que es muy rica también, y después como que no es un lugar de lujo, que vos vayas, no sé, pones un hotel nuevo en la península, sino que tiene toda una historia (...), se come bien, el restaurant es muy bueno, (...), los guías, el personal. Es como que se mantiene un equilibrio bueno. (PST-5, Camarones, 25 de febrero de 2018)

La presencia de áreas protegidas es otro de los factores que incide positivamente en la atractividad. Las mismas actúan como un instrumento estratégico de los destinos turísticos; en palabras de Vereda (2004) "las áreas protegidas de un destino se erigen como un fuerte referente que genera desplazamientos especialmente vinculados a prácticas de turismo de naturaleza y particularmente de ecoturismo"(p. 103). Puerto Deseado y Camarones poseen sitios de visita incluidos en áreas protegidas y si bien reflejan diferentes jurisdicciones que podrían suscitar conflictos en relación a su manejo, los entrevistados afirman que esta característica permite posicionar a los espacios como sitios altamente valorados y con gran potencial para la actividad turística.

Nosotros tenemos acá el Parque Nacional Interjurisdiccional Marino, Isla Pingüino. Entonces, donde nos pongan el logo de "Parque" ya cambiamos la situación. Por eso te digo, son hechos (...). (OP-4, Puerto Deseado, 2 de marzo de 2018)

Es un área poco visitada... entonces la actividad de cruceros creo que también lo pueden disfrutar... lo pueden disfrutar los turistas, eh... el sendero es elevado, o sea que no hay que ceder el paso cuando ellos pasan y eso hace que el pingüino no se estrese, por más que tenga gente... va a tener gente arriba, otra fortaleza... mmm no se me ocurre ahora. (OP-5, Camarones, 27 de febrero de 2018)

Con las nuevas formas de elegir y reconstruir los lugares con atractivos, se participa de la apropiación de territorios que se despegan del lugar para transformarse en símbolos de consumo y focos de atracción social, expresa Cammarata (2006). Sin embargo, para que los mismos puedan ser incorporados en la práctica turística, en necesario reconocer la aptitud que poseen. Trabajar en la búsqueda y consolidación de actividades que permitan disfrutar de la visita en más de un sentido, otorgaría la posibilidad de demostrar la versatilidad que tienen los destinos frentes a una demanda que es cambiante y dinámica.

Tenemos un lugar paisajísticamente privilegiado, porque la variedad que vos ves, si has tenido la oportunidad de recorrer las playas, la variedad de playas y numerosas y una es más bonita que la otra, o sea paisajísticamente lo mires por donde lo mires es un espectáculo, tiene un valor histórico muy importante, que es, por muchos, desconocido. (PST-7, Camarones, 25 de febrero de 2018).

Desde esta perspectiva, los recursos naturales y culturales que distinguen a las localidades dan la posibilidad de realizar una interesante variedad de actividades. Las mismas

${ }^{3}$ Ver https://www.pagina12.com.ar/diario/suplementos/turismo/9-2129-2011-08-14.html consultado el 01/08/2019. 
son analizadas según la variedad de tipos de turismo que pueden realizarse considerando la afirmación realizada por Schinelli \& Vacca (2007) quienes aseguran que "La región cuenta con muchos otros atractivos vinculados a la naturaleza que favorecen el desarrollo de nuevas dimensiones de la actividad, tales como el turismo de intereses especiales, científico, cultural y de aventura"(p. 212). Desde este marco, los resultados reflejan la posibilidad de combinar diferentes actividades en un mismo sitio de visita (tabla 2) y así reflejan la potencialidad de sus elementos territoriales para complementarse y maximizar su aprovechamiento.
Un factor clave para poder comprender la posición que tienen los sitios de visita para incluirse en el turismo de cruceros es el tiempo que conlleva su visita. Pensar el mismo implica analizarlo no solo en relación a la duración de la visita en los sitios propuestos (tiempo de percepción), sino también en función de cuánto se demora en llegar y regresar del mismo (tiempo de traslado). Este dato no es menor si se tiene en cuenta que el tiempo del buque en puerto es condicionante para el desarrollo de la actividad, por tanto, debe ser considerado al momento de ofrecer actividades y productos que se adecuen a ello.

Tabla 2

Opciones de tipos de turismo posibles de desarrollar.

\begin{tabular}{|c|c|c|c|c|c|c|c|c|}
\hline & TIPOS DE T & RISMO & & & & & & \\
\hline Sitios de Visita & Sol y playa & Activo & Cultural & Científico & De Salud & De Deporte & $\begin{array}{l}\text { Intereses } \\
\text { especiales }\end{array}$ & Convencional \\
\hline \multicolumn{9}{|l|}{ Puerto Deseado } \\
\hline Museo del Pueblo & & & $\mathrm{x}$ & $\mathrm{x}$ & & & $x$ & $x$ \\
\hline Museo Ferroviario & & & $\mathrm{x}$ & $\mathrm{x}$ & & & $x$ & $\mathrm{x}$ \\
\hline Circuito "De cara a la Livertá" & & & $\mathrm{x}$ & $\mathrm{x}$ & & & $\mathrm{x}$ & $x$ \\
\hline Circuito "Derrotero del Corsario" & & & $x$ & $x$ & & & $x$ & $x$ \\
\hline Museo Municipal Mario Brozoski & & & $\mathrm{x}$ & $x$ & & & $x$ & $x$ \\
\hline Museo Policlínico & & & $x$ & $x$ & & & $x$ & $x$ \\
\hline Campamento de Darwin & & $x$ & $\mathrm{x}$ & $x$ & & & $x$ & $x$ \\
\hline Ría Deseado & & $x$ & & $x$ & & $x$ & $x$ & $x$ \\
\hline Isla Pingüino & & $x$ & $x$ & $x$ & & $x$ & $x$ & $x$ \\
\hline Cerro Van Noort & & $x$ & $x$ & $x$ & & $x$ & $x$ & $x$ \\
\hline Gruta de Lourdes & & & $x$ & $x$ & & & $x$ & $x$ \\
\hline Piedra Toba & & $x$ & & $x$ & & $x$ & $x$ & $x$ \\
\hline Cañadón del puerto & & $x$ & & $x$ & & $x$ & $x$ & $x$ \\
\hline Hoorn & & $x$ & $x$ & $\mathrm{x}$ & & $x$ & $x$ & $x$ \\
\hline Derrotero Darwin & & $x$ & $x$ & $x$ & & $x$ & $x$ & $\mathrm{x}$ \\
\hline Camino Costero & & $x$ & & $x$ & & & $x$ & $x$ \\
\hline
\end{tabular}


Tabla 2 (continuación)

Opciones de tipos de turismo posibles de desarrollar.

\begin{tabular}{|c|c|c|c|c|c|c|c|}
\hline Cuevas de los Leones & $x$ & $x$ & $x$ & $x$ & & $x$ & $x$ \\
\hline \multicolumn{8}{|l|}{ Camarones } \\
\hline Museo Provincial "Familia de Perón" & & & $x$ & $x$ & & $x$ & $x$ \\
\hline Circuito Pedestre & & & $x$ & & & $x$ & $x$ \\
\hline Sendero de interpretación ambiental & $x$ & $x$ & & $x$ & & $x$ & $x$ \\
\hline Caleta Sara & $x$ & & $x$ & & $x$ & $x$ & $x$ \\
\hline Museo "El rincón de la historia" & & & $x$ & $x$ & & $x$ & $x$ \\
\hline $\begin{array}{l}\text { Parque Interjurisdiccional Marino } \\
\text { Costero }\end{array}$ & & $x$ & $x$ & $x$ & $x$ & $x$ & $x$ \\
\hline Pingüinera - Cabo dos Bahías & $x$ & $x$ & & $x$ & & $x$ & $x$ \\
\hline Bahía Bustamante & $x$ & $x$ & $x$ & $x$ & $x$ & $x$ & $x$ \\
\hline
\end{tabular}

Fuente: Elaboración propia.

Desde esta mirada surge una diversidad de propuestas (figura 3), con sitios de visita que no requieren un tiempo mayor a las tres horas, contra aquellos que manifiestan una duración que puede implicar más de seis horas. La duración de éstas varía según su distancia, el recorrido que realicen y los atractivos que visiten. Esta variable es también considerada en las opiniones de los entrevistados quienes destacan que en sus esporádicos arribos siempre buscaron coordinar el tiempo de visita con la permanencia del buque y así responder satisfactoriamente a esta exigencia.

El crecimiento de la actividad debe acompañarse de un incremento significativo de la oferta de servicios vinculados al sector, aseguran Schinelli \& Vacca (2007). Esta variable forma parte de la aptitud y, en este sentido, la comunicación, la inclusión de los sitios de visita en excursiones regulares y la presencia de equipamiento turístico-recreativo pueden actuar o no como ventajas competitivas que posicionen a las localidades. En relación a la comunicación, fue particularmente destacada por los entrevistados en Camarones, quienes aseguran que, al ser una localidad pequeña, con deficiencias en la comunicación, su ausencia es un factor que no favorece la consolidación del destino.

Internet (...) es un medio de comunicación muy importante y por ahí para nosotros es un poco escaso, no todo el pueblo tiene. Entonces por ahí mucha gente llega acá sin saber que es Camarones y después cuando se va, se va con cosas que no sabía que tenía esto, que tenía lo otro. (OM-4, Camarones, 26 de febrero de 2018)

Otro de los factores considerados corresponde a su inclusión en excursiones regulares. Ambas localidades plantean realidades diferentes que acuerdan con su posición actual como destinos turísticos. Puerto Deseado ofrece como excursiones regulares aquellos sitios de visita que están ya posicionados. Ante ello los entrevistados aseguran que la organización permite aprovechar sin inconveniente todos los atractivos que en esos sitios se encuentran y, favorecidos por la menor concentración de visitantes, consideran que son espacios que aún tienen mucho potencial para aprovechar.

En Camarones no se han logrado aún posicionar excursiones regulares como parte de su oferta turística, con excepción de la visita a la Reserva Provincial Cabo Dos Bahías. Si bien, hay una empresa habilitada para brindar el servicio, la falta de promoción estatal como así también de inversión conlleva depender fuertemente de otras localidades para poder dar respuesta a una posible demanda. De esta manera, se dificulta la posibilidad de endogeneizar los beneficios que los sitios de visita y sus atractivos poseen.

No. Se diversificaba. Se hacía terrestre, entonces era rotativo. Mientras unos iban por tierra, otros navegaban y así. El terrestre, en esa época se hizo a Miradores de Darwin, con distintas traffics, se los llevaba y no, bien. Digamos, en conjunto porque por ahí no había 

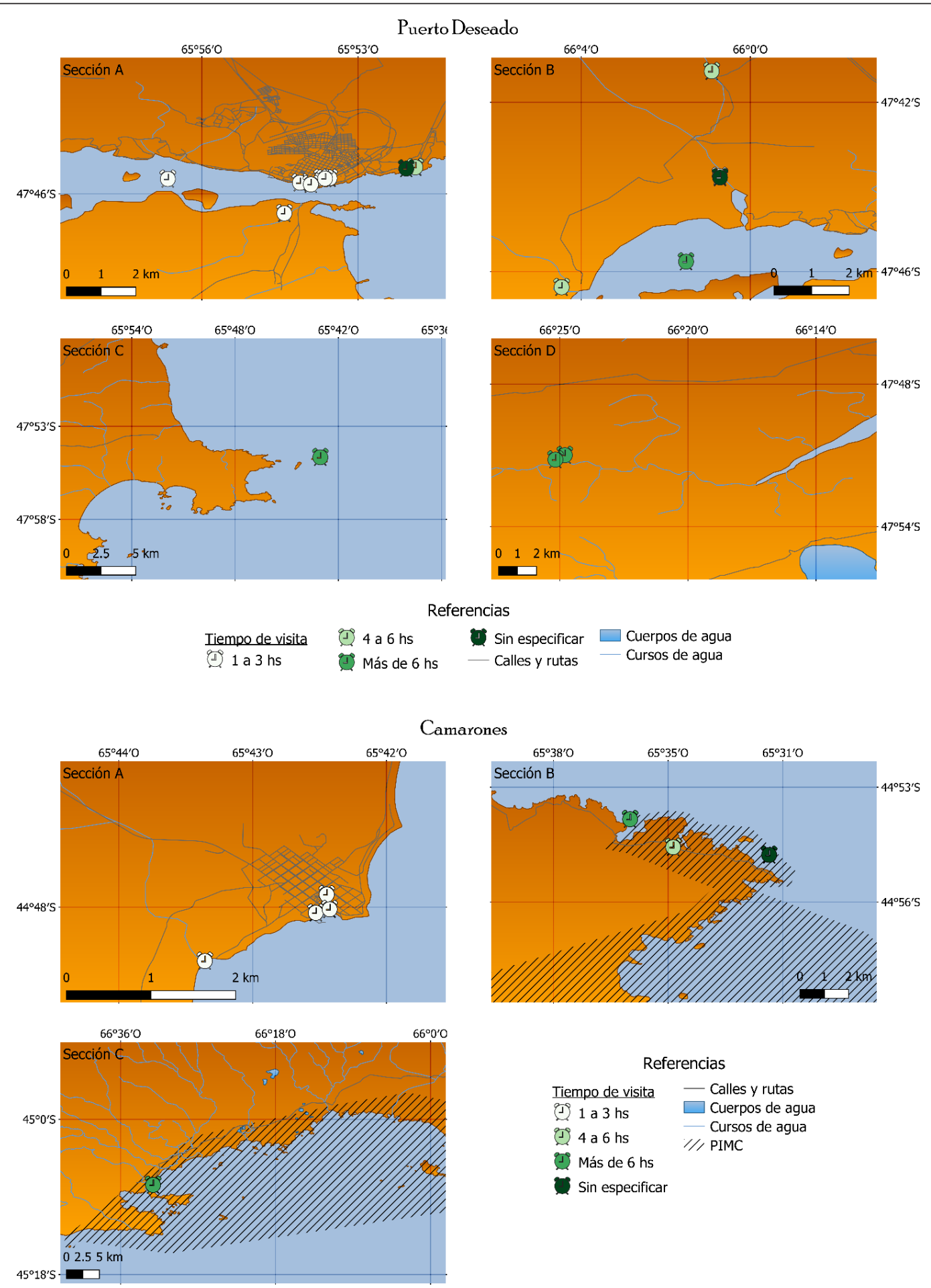

Referencias

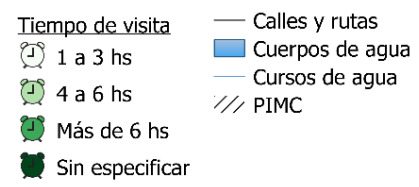

Figura 3. Duración estimada de la visita. Fuente: Elaboración propia con base en QGis 3.4.0. 
muchos guías, pero más o menos que hablen, sobre todo bilingüe. Salía bien. (PST-4, Puerto Deseado, 2 de marzo de 2018)

Compramos una embarcación nueva, moderna, de última generación hecha acá en el país, pero tampoco dio resultado... y bueno hacemos excursiones las que llegan para hacerlo. Además, no está promocionado y la gente que viene acá no viene con la intención de ver fauna porque no se ha promocionado. (PST-6, Camarones, 25 de febrero de 2018)

Por último, se analizaron los sitios de visita en función a su accesibilidad. Desde su condición de acceso, muchos de ellos son de carácter libre y gratuito si se llevan a cabo por cuenta propia. Sin embargo, en el contexto de una visita resultado del arribo de cruceros, donde se debe tener en cuenta la dependencia que poseen al itinerario de viaje del buque, la mitad de ellas debería pagarse para que puedan llevarse a cabo, en tiempo y forma. Ante ello, en Puerto Deseado, la ganancia la absorben empresas locales, en cambio en Camarones, muchas veces son empresas que provienen de otras localidades las que concretan las visitas, quedando los trabajadores locales ajenos a ella.

El crucerismo como está viniendo en este momento, amarra en la dársena, vienen los colectivos de $\mathrm{AV}^{4}$, los guías de AV, los bajan, los suben, los llevan al área protegida, los traen y los suben otra vez, eso no sirve. (PST-7, Camarones, 26 de febrero de 2018)

Otro de los factores referidos a la accesibilidad es el transporte público. Ninguna de las localidades posee un transporte público que incluya a los sitios de visita ofrecidos, con excepción de aquellos que se ubiquen en el centro. Ante esto, es necesario recurrir a la contratación del transporte para realizar el recorrido. Los sitios de visita se distribuyen espacialmente ubicándose a diferentes distancias en el hinterland turístico, algunos de ellos llegan a superar los $20 \mathrm{~km}$ (figura 4).

Poseer transporte que asegure un tiempo de traslado prudencial para apreciar los atractivos y regresar al buque en el horario fijado es aún un desafío en términos de transporte público. Desde el ámbito privado las localidades han sabido aprovechar esta situación, Puerto Deseado es quien refleja los réditos económicos directamente en su territorio, gracias a la consolidación de empresas locales con capacidad de responder a esta demanda. La interseccionalidad del turismo y la especial característica
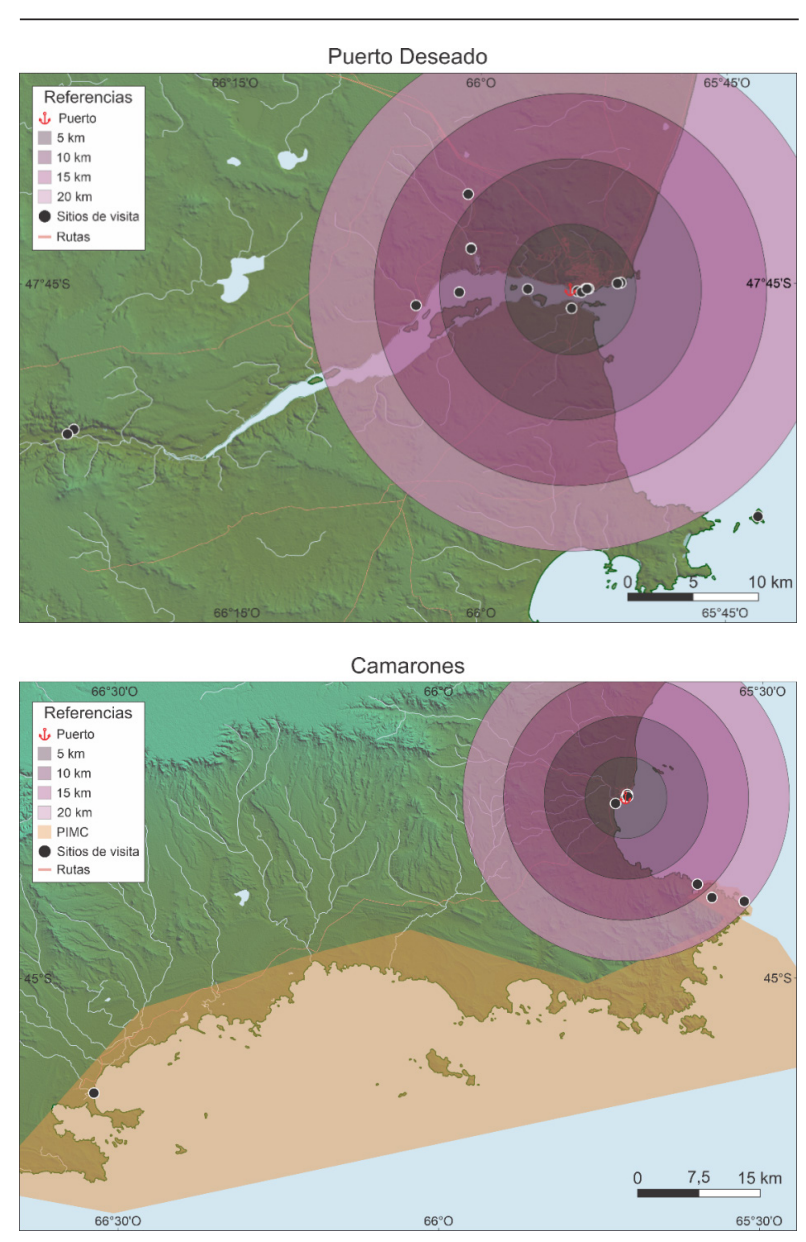

Figura 4. Distancia de los sitios de visita. Fuente: Elaboración propia.

de cadena de valor le permite actuar como multiplicador económico, aseguran Schinelli \& Vacca (2007); sin embargo, para que esto genere un desarrollo real y genuino los resultados deben verse en el propio territorio y esta situación no se refleja por igual desde los actores claves. En Camarones no logran posicionarse como empresas competitivas y con capacidad de responder a la demanda, siempre están a la sombra de empresas que se encuentran en otras localidades y no consolidan un trabajo en conjunto que les permita generar beneficios mutuos.

Los capturaban en los muelles, los subían a los colectivos y salían todos en caravana, regresaban y los embarcaban, calcula que el crucero llegaba a las seis de la mañana y a las cuatro de la tarde ya se iba, entonces eso no. Les sirve a ellos, a nosotros no. (PST-7, Camarones, 26 de febrero de 2018)

${ }^{4}$ Empresa de turismo receptivo radicada en Puerto Madryn. 
Por último, se destaca la relación que existe entre la accesibilidad temporal de los sitios de visita y la temporada de cruceros (figura 5). A partir de los resultados obtenidos se muestran que los sitios de visita son compatibles con la temporada de cruceros, pues el mayor porcentaje de estos son accesibles en temporada de verano o bien durante todo el año. Este dato no es menor si se tiene en cuenta, como expresa Vejsbjerg (2013), que para que un turista potencial elija un destino, requiere en primera instancia un atractivo inicial, accesibilidad y servicios. Este argumento puede ser rápidamente aplicado al turismo de cruceros el cual exige destinos que les ofrezcan experiencias que enriquezcan el itinerario.
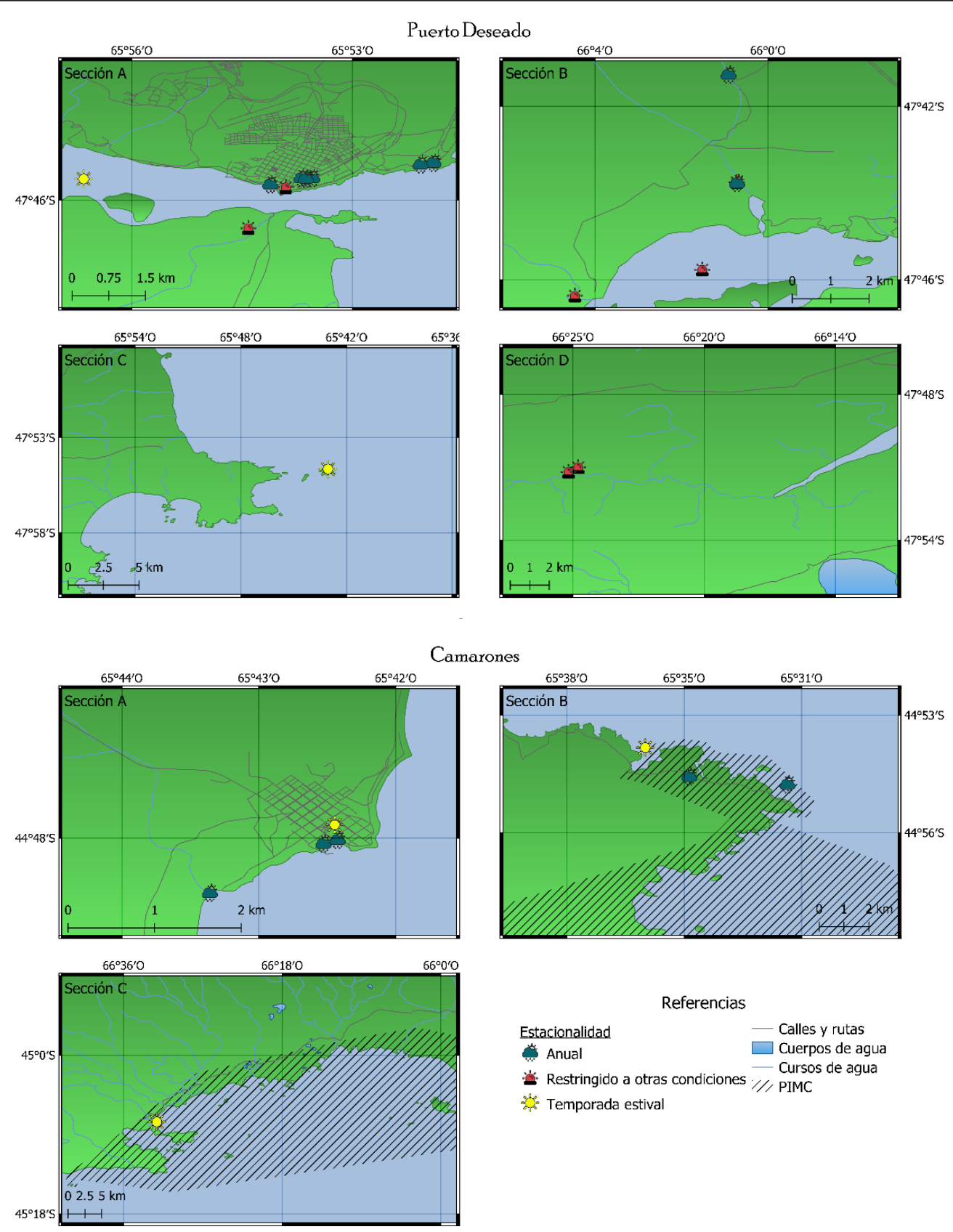

Figura 5. Estacionalidad de los sitios de visita. Fuente: Elaboración propia con base en QGis 3.4.0. 


\section{La prestación de servicios}

Proporcionar experiencias positivas requiere de un conjunto de servicios que lo respalde, como un sistema de engranajes de equipamiento e infraestructura que esté en condiciones de brindar respuesta y calidad (González \& Mendieta, 2009; Vera et al., 1997;) (tabla 3). Ambas localidades aseguran que la escasez de equipamiento se presenta como una gran limitante. Se establece aquí un doble discurso, por un lado, la necesidad de demanda para que sea justificada la inversión, por el otro, la falta de oferta como un factor que disminuye el interés por conocer estos puertos.

La escasa cantidad de equipamiento lleva a depender fuertemente de los centros urbanos más cercanos para poder responder a la demanda que realizan las empresas de cruceros. Esto conlleva que las ganancias generadas, los nexos con las empresas, los recursos humanos empleados, entre otros, sean exógenos a sus localidades produciéndose un vacío en las ventajas competitivas que las mismas podrían aprovechar. El acceso a las redes de transporte y comunicación, el equipamiento receptivo y la estructura de servicios en general encuadran las formas técnicas del desarrollo turístico-recreativo, pero además conforman una nueva territorialidad con nuevas formas de sociabilidad y división espacial del consumo (Cammarata, 2006). El relevamiento del equipamiento evidencia algunas particularidades basadas no solamente a su presencia física, sino también a las estrategias que cada localidad debería aplicar para potenciar la actividad.

Este año se hizo un curso de guías, hay como una camada de doce guías nuevos. El problema que tenemos ahora es el guía bilingüe, digamos. Y la falta de una continuidad. Al no ser un destino de mucho turismo, es como que, al perder la continuidad, la gente que por ahí quiere trabajar de guía, termina trabajando de otra cosa, que le dé una seguridad, una estabilidad económica. (PST-4, Puerto Deseado, 2 de marzo de 2018)

Nosotros servicios de transporte no tenemos (...), hoy por hoy creo que hay uno... bueno siempre fue ese el tema, ¿no cierto? El traslado de acá a Cabo dos Bahías y bueno en esa época contrataban autos particulares, eran como más de 30 autos que se hicieron su changuita como quien dice y bueno todo el mundo chocho. (OM-4, Camarones, 26 de febrero de 2018)

Respecto al desarrollo de infraestructura portuaria, si bien las características naturales de abrigo y profundidad de
Tabla 3

Equipamiento que poseen los puertos para ofrecer Turismo de Cruceros.

\begin{tabular}{|c|c|c|}
\hline Categoría & $\begin{array}{l}\text { Puerto Deseado (año } \\
\text { 2018) }\end{array}$ & Camarones (año 2018) \\
\hline Restauración & 25 & 12 \\
\hline $\begin{array}{l}\text { Prestadores } \\
\text { de servicios }\end{array}$ & 3 & $\begin{array}{l}2 \text { - Solo uno ubicado } \\
\text { en la localidad de } \\
\text { Camarones. }\end{array}$ \\
\hline $\begin{array}{l}\text { Guías de } \\
\text { turismo }\end{array}$ & $\begin{array}{l}\text { Se conocen programas } \\
\text { de capacitación, pero } \\
\text { no hay información } \\
\text { específica del número de } \\
\text { guías habilitados. }\end{array}$ & $\begin{array}{l}5 \text { - Guías de sitio } \\
\text { provinciales. } \\
1 \text { - Guía de Pesca. }\end{array}$ \\
\hline & $\begin{array}{l}\text { Sin información del } \\
\text { número exacto. }\end{array}$ & $\begin{array}{l}3 \text { - de vía terrestre. } \\
\text { 1- de vía acuática. }\end{array}$ \\
\hline Transporte & $\begin{array}{l}\text { La localidad no cuenta } \\
\text { con empresas que se } \\
\text { dediquen al alquiler } \\
\text { de automóviles. En } \\
\text { caso de ser necesario } \\
\text { debe realizarse en una } \\
\text { localidad cercana. }\end{array}$ & $\begin{array}{l}\text { La localidad no cuenta } \\
\text { con empresas que se } \\
\text { dediquen al alquiler } \\
\text { de automóviles. En } \\
\text { caso de ser necesario } \\
\text { debe realizarse en una } \\
\text { localidad cercana. }\end{array}$ \\
\hline
\end{tabular}

Fuente: Elaboración propia.

aguas y sus ubicaciones geográficas conforman ventajas comparativas con las que pueden contar los puertos, las obras de mejoramiento, así como la organización y gestión de estos expresan las ventajas competitivas (tabla 4). Este dato no es menor si se tiene en cuenta las particularidades naturales que caracterizan a las localidades, dadas por su geomorfología y la amplitud de mareas. Esto implica, como asegura Otero (2000), que el espacio turístico, como espacio productivo, requiera de instalaciones, equipamiento e infraestructura que posibiliten y aseguren la oferta de servicios.

Relacionado a la operatividad del puerto y complementando a la infraestructura, se destacan los servicios marítimos que los puertos ofrecen (tabla 5). Reconocer el rol que tienen estos indicadores permite entender la capacidad de respuesta ante el arribo de buques de cruceros, pero además y fundamentalmente esboza la posición competitiva. Un puerto, en el marco de la globalización, debe revalorizarse como espacio, asegura Martner Peyrelongue (1999), pues el mismo debe ser pensado como un lugar, como una región atravesada por los movimientos y por la velocidad del tiempo, con capacidad de marcar diferencias entre lo interno y lo externo.

Las localidades poseen capacidades portuarias que concuerdan con el grado de desarrollo que tienen. Puerto Deseado destaca que los servicios portuarios consolidados son consecuencia de su trayectoria en la economía pesquera 
Tabla 4

Principales características portuarias.

\begin{tabular}{|c|c|c|}
\hline $\begin{array}{l}\text { Infraestructura } \\
\text { portuaria e } \\
\text { instalaciones }\end{array}$ & Puerto Deseado & Camarones \\
\hline $\begin{array}{l}\text { Longitud del } \\
\text { muelle (actual) }\end{array}$ & 739,11 metros. & 9 metros. \\
\hline Profundidad & $\begin{array}{l}\text { Para los sitios } 1 \text { y } 2 \\
\text { de } 11 \text { metros, sitio } 3 \text { y } \\
4 \text { de } 9 \text { metros, sitios } 5 \\
\text { y } 6 \text { de } 10,5 \text { metros. }\end{array}$ & 5 metros. \\
\hline $\begin{array}{l}\text { Sistemas de } \\
\text { defensas }\end{array}$ & $\begin{array}{l}\text { Escudos metálicos } \\
\text { recubiertos con } \\
\text { material antifícción } \\
\text { y defensas elásticas } \\
\text { con un diámetro de } \\
800 \text { milímetros a } \\
1000 \text { milímetros y con } \\
\text { bitas de } 30 \text { toneladas, } \\
60 \text { toneladas, } 80 \\
\text { toneladas y } 100 \\
\text { toneladas; en ambos } \\
\text { casos según el sitio. }\end{array}$ & $\begin{array}{l}\text { Defensas dispuestas } \\
\text { en forma alternada en } \\
\text { posición vertical. }\end{array}$ \\
\hline $\begin{array}{l}\text { Condición } \\
\text { general }\end{array}$ & $\begin{array}{l}\text { Estructura de } \\
\text { hormigón donde se } \\
\text { opera con cargas de } \\
\text { pesca, carga general, } \\
\text { carga frigorífica y } \\
\text { contenedores. }\end{array}$ & $\begin{array}{l}\text { Estructura de hormigón } \\
\text { donde se opera con } \\
\text { carga de pesca. }\end{array}$ \\
\hline $\begin{array}{l}\text { Terminal de } \\
\text { depósito para } \\
\text { contenedores }\end{array}$ & $\begin{array}{l}\text { Plazoleta fiscal } \\
\text { para contenedores, } \\
\text { pavimentada y con } \\
\text { cerco perimetral, de } \\
5.095 \text { metros2 }\end{array}$ & Sin información. \\
\hline $\begin{array}{l}\text { Sistema de } \\
\text { amarre }\end{array}$ & $\begin{array}{l}\text { Consta de } 4 \text { frentes } \\
\text { operativos, con } \\
\text { anchos para las } \\
\text { operaciones que van } \\
\text { de los } 17 \text { metros a los } \\
30 \text { metros, con una } \\
\text { superficie operativa } \\
\text { total de } 15.000 \\
\text { metros2 }\end{array}$ & $\begin{array}{l}\text { Un frente de amarre } \\
\text { dispuesto en la bahía, } \\
\text { con ancho para } \\
\text { operaciones de hasta } \\
26 \text { metros. Barrera de } \\
\text { contención en el sector } \\
\text { sudeste. }\end{array}$ \\
\hline
\end{tabular}

Fuente: Elaboración propia con base en sitios web www.marinetraffic.com; www.uneposc.com.ar

y que deberían trabajar en aquellas áreas o ítems que impliquen una necesidad directa con el turismo de cruceros. Por su parte, Camarones denota una incipiente capacidad portuaria, asociada a su actividad pesquera, pero sin proyectos que tengan en vista fortalecer el sector.

Los puertos desempeñan un rol fundamental en la concreción del turismo de cruceros no solo por ser receptores del arribo de los buques sino, además, porque los mismos actúan como nexos entre el foreland y el hinterland turístico, y cuando esta relación no es lo suficientemente fuerte se genera un espacio de desvinculación que caracteriza a
Tabla 5

Opinión de los entrevistados sobre los servicios portuarios.

\begin{tabular}{|c|c|c|}
\hline $\begin{array}{l}\text { Servicios } \\
\text { portuarios }\end{array}$ & Puerto Deseado & Camarones \\
\hline Muellaje & $\begin{array}{l}\text { Si bien en términos } \\
\text { técnicos cuenta con los } \\
\text { servicios necesarios, no } \\
\text { tiene la capacitación ni } \\
\text { experiencia requerida para } \\
\text { hacer frente a la demanda. }\end{array}$ & $\begin{array}{l}\text { No expresa } \\
\text { información. }\end{array}$ \\
\hline Practicaje & $\begin{array}{l}\text { No poseen prácticos } \\
\text { permanentes, requieren } \\
\text { de la colaboración de } \\
\text { localidades más grandes, } \\
\text { en ocasiones provienen de } \\
\text { Ushuaia. }\end{array}$ & $\begin{array}{l}\text { No poseen prácticos, } \\
\text { requieren de la } \\
\text { colaboración de } \\
\text { localidades más } \\
\text { grandes. }\end{array}$ \\
\hline Mercadería & $\begin{array}{l}\text { Los proveedores marítimos } \\
\text { pueden responder a la } \\
\text { potencial demanda para el } \\
\text { abastecimiento de víveres. }\end{array}$ & $\begin{array}{l}\text { No expresa } \\
\text { información. }\end{array}$ \\
\hline Estiba & $\begin{array}{l}\text { Poseen } 129 \text { estibadores } \\
\text { que trabajan de forma } \\
\text { permanente en el puerto, } \\
\text { dependiendo de la } \\
\text { operatoria se pueden } \\
\text { tomar temporales. }\end{array}$ & $\begin{array}{l}\text { La estiba funciona } \\
\text { acorde a la demanda } \\
\text { actual del puerto, } \\
\text { contando en el } 2016 \\
\text { con un total de } \\
\text { cuarenta estibadores. }\end{array}$ \\
\hline Residuos & $\begin{array}{l}\text { La municipalidad brinda el } \\
\text { servicio de disposición final } \\
\text { de residuos. }\end{array}$ & $\begin{array}{l}\text { El retiro y tratamiento } \\
\text { de residuos no } \\
\text { representa problemas } \\
\text { en términos de la } \\
\text { demanda actual, } \\
\text { pero no especifica } \\
\text { quien actúa como } \\
\text { responsable de la } \\
\text { disposición final. }\end{array}$ \\
\hline Combustible & $\begin{array}{l}\text { Cuenta con una planta } \\
\text { de combustible (YPF } \\
\text { Planta Puerto Deseado). } \\
\text { Descarga del buque } \\
\text { tanque a los tanques } \\
\text { y dispone de un } \\
\text { almacenamiento de cinco } \\
\text { millones de litros que se } \\
\text { distribuye por ducto a los } \\
\text { buques. }\end{array}$ & $\begin{array}{l}\text { El aprovisionamiento } \\
\text { depende de } \\
\text { Comodoro Rivadavia. }\end{array}$ \\
\hline Agua & $\begin{array}{l}\text { A partir de la planta de } \\
\text { ósmosis pueden hacer } \\
\text { frente a la provisión de } \\
\text { agua sin inconveniente. }\end{array}$ & $\begin{array}{l}\text { Depende de las } \\
\text { localidades aledañas, } \\
\text { principalmente } \\
\text { Comodoro Rivadavia. }\end{array}$ \\
\hline $\begin{array}{l}\text { Taller de } \\
\text { reparación } \\
\text { naval }\end{array}$ & $\begin{array}{l}\text { Cuenta con cuatro } \\
\text { talleres de reparación } \\
\text { naval privados que están } \\
\text { operativos todo el año, } \\
\text { La máxima ocupación y } \\
\text { demanda del servicio se } \\
\text { produce durante los meses } \\
\text { de verano, cuando los } \\
\text { buques pesqueros entran } \\
\text { en reparación. }\end{array}$ & $\begin{array}{l}\text { No poseen taller de } \\
\text { reparación naval, } \\
\text { depende de las } \\
\text { localidades aledañas } \\
\text { para dar respuesta a } \\
\text { esta demanda. }\end{array}$ \\
\hline
\end{tabular}

Fuente: Elaboración propia. 
los territorios como puntos de quiebre, lo que dificulta el desarrollo de la actividad. En este marco, cada puerto expresa realidades completamente diferentes. En opinión de los entrevistados, Puerto Deseado posee los servicios e infraestructura necesarios para responder al turismo de cruceros. Su experiencia y trayectoria en la actividad pesquera ha permitido equipar $y$ fortalecer al puerto con las instalaciones necesarias. Si bien destacan la importancia de reparar y/o mejorar algunas secciones del puerto, lo que se plantea como limitante responde a la posibilidad de compatibilizar cruceros y pesca, considerando que, ante el arribo de buques de pasajeros, podrían generarse tensiones en la operatividad y logística del puerto.

En Camarones, si bien la actividad permitiría un cambio en la localidad, otorgaría diversificación y "vida" al pueblo, en términos de capacidad de respuesta del puerto se destaca que aún no tienen las herramientas necesarias para hacer frente a buques de pasajeros. Dependen fuertemente de las grandes localidades que se encuentran aledañas a ella, las cuales estarían en condiciones de abastecer al puerto con los servicios necesarios.

\section{Conclusiones}

El turismo de cruceros se produce en un entorno de constante competencia y el arribo de sus buques a una localidad es sinónimo de grandes expectativas en relación a las posibilidades de desarrollo. Sin embargo, no alcanza con posicionarse como un destino de interés, sino entender cómo se relacionan y se ponen en marcha las fortalezas territoriales que poseen estas localidades a fin de lograr una participación activa, endogeneizando y aprovechando las externalidades que conlleva la actividad. Así, la diversidad y cantidad de sitios de visita posicionan positivamente a los puertos como posibles destinos de cruceros, donde su impronta prístina, de escasa alteración y, en algunos casos, su condición de área protegida permite posicionarlos favorablemente ante otros puertos y áreas de influencia. La singularidad de los sitios propuestos posiciona a las localidades como espacios con condiciones territoriales de interés para el desarrollo del turismo de cruceros, gracias a la posibilidad de brindar experiencias únicas que solo allí se pueden disfrutar.

En relación a la aptitud, asociada a los diferentes tipos de turismo que cada sitio de visita posee, se destaca una interesante variedad y diversidad de propuestas que pueden beneficiar las posibilidades de consolidar esta actividad, al brindar mayores opciones de aprovechamiento. Al analizarlo en relación al tiempo de permanencia que dispondría el buque en puerto y, considerando, el rol que tiene el mismo en la concreción de un destino, la afirmación de adaptarse a las diferentes exigencias permite considerarlo como una característica con capacidad para posicionar a los puertos como una alternativa para la oferta de cruceros.

La accesibilidad también fue planteada como un componente fundamental y en las localidades analizadas se observan que algunas variables requieren de mayor trabajo que otras. Si bien se destaca que la posibilidad de visitar los atractivos es compatible con el período del año en el cual se desarrolla la actividad de cruceros, aspectos relacionados con el transporte y la administración de los espacios no han sido aún abordados en profundidad para asegurar la accesibilidad de estos. En Camarones su falta de desarrollo en términos de turismo conlleva requerir de la intervención de localidades aledañas continuamente, lo que genera una disputa en relación dónde quedan los beneficios que la actividad genera.

Así como los sitios de visita son puestos en discusión como componentes territoriales que revisten, o no, competitividad de los puertos, la prestación de servicios y equipamiento portuario también influyen en la consolidación de los destinos y aquí se destacan situaciones disímiles. Puerto Deseado con un desarrollo más claro y consolidado ha logrado responder a una demanda esporádica de cruceros sin inconveniente, pero asegura que la localidad requiere de inversión y proyección para que la actividad turística se consolide. Camarones aún no ha logrado posicionarse desde este marco y es la falta de servicios uno de los limitantes más fuerte con los que se encuentra para el desarrollo de la actividad.

\section{Agradecimientos}

Las autoras desean agradecer a CONICET por respaldar la investigación a través de la Beca Interna Doctoral y a los proyectos de investigación PIDUNTDF 2016 y 2018 pertenecientes a la Universidad Nacional de Tierra del Fuego, Antártida e Islas del Atlántico Sur por financiar el trabajo. A la docente Lic. Mariana Morgavi, la Mg. María Laura Borla y la Prof. Patricia Galván por su compañía y colaboración con las entrevistas. Por último, a los residentes de las localidades de Camarones y Puerto Deseado por su amabilidad y predisposición para colaborar en la investigación. 


\section{Referencias}

Alcerreca Molina, L. \& Salazar Estrada, A. (24 - 27 de septiembre 2014). Turismo de cruceros, propuesta para la diferenciación de la oferta turística en Puerto Progreso, Yucatán por medio de la puesta en valor de la identidad cultural de la comunidad receptora, en beneficio de la misma [Trabajo Presentado]. Congreso de Investigación Turística Aplicada. México.

Ávila Bercial, R. \& Barrado Timón, D. A. (2005). Nuevas tendencias en el desarrollo de destinos turísticos: Marcos conceptuales y operativos para su planificación y gestión. Cuadernos de turismo, 15, 27-43. Recuperado de https://digitum.um.es/digitum/ bitstream/10201/13043/1/1302199.pdf

Bandieri, S. (2005). Historia de la Patagonia. Buenos Aires: Editorial Sudamericana.

Bertoncello, R. (2002). Turismo y territorio. Otras prácticas otras miradas. Aportes y transferencias, 2948. Recuperado de http://nulan.mdp.edu.ar/259/1/ Apo2002a6v2pp29-50.pdf

Bertoncello, R. (2010). Investigación en Turismo. Logros y Desafíos desde una Perspectiva Latinoamericana. Aportes y Transferencias, 1(14), 11-21. Recuperado de http://nulan.mdp.edu.ar/id/eprint/1484

Berumen, S. (2006). Competitividad y desarrollo local en la economía global. Madrid: Editorial ESIC.

Boisier, S. (1997). El vuelo de una cometa. Una metáfora para una teoría del desarrollo territorial. Revista EURE-Revista de Estudios Urbano Regionales, 23 (69). Recuperado de http://eure.cl/index.php/eure/ article/view/1159

Brida, J. G., Bukstein, D., Garrido, N., Tealde, E. \& Zapata Aguirre, S. (2010). Impacto económico del turismo de cruceros: un análisis del gasto de los cruceristas que visitan el Caribe colombiano (Documento de investigación $\mathrm{n}^{\circ}$ 58). Universidad ORT, Uruguay. Recuperado de https://dspace. ort.edu.uy/bitstream/handle/20.500.11968/2780/ d o c u m e n to d e investigacion 58 . pdf? sequence $=1 \&$ is Allowed $=y$.

Brida, J. G., Riaño, E., Such-Devesa, M. J. \& ZapataAguirre, S. (2012). Valoración del turismo de cruceros por parte de la comunidad local: Cartagena de Indias. Scripta Nova: revista electrónica de geografia y ciencias sociales, 16(389). Recuperado de http://www.ub.edu/geocrit/sn/sn-389.htm

Brida, J. G., Riaño, E. \& Aguirre Zapata, S. Z. (2012). Percepciones de los residentes acerca de los impactos del turismo de cruceros en la comunidad: un análisis factorial y de clústeres. Cuadernos de Turismo, 29, 79-107. Recuperado de https://revistas.um.es/ turismo/article/view/153311

Bustos Cara, R. (2001). Identidad, turismo y territorio locales. La permanente construcción de valores territoriales. Aportes y Transferencias, 1 (5), 11-28. Recuperado de http://nulan.mdp.edu.ar/id/eprint/244

Butler, M. (2008). Turismo de cruceros. Situación actual y tendencias. Organización Mundial del Turismo.

Callizo Soneiro, J. (1991). Aproximación a la geografía del turismo. Madrid: Editorial Síntesis.

Cammarata, E. B. (2006). El turismo como práctica social y su papel en la apropiación y consolidación del territorio. En A. I. Geraiges de Lemos, M. Arroyo, y M. L. Silveira (Eds.), América Latina: cidade, campo e turismo (pp. 351-366). CLACSO. Recuperado de: http://bibliotecavirtual.clacso.org.ar/ar/libros/ edicion/lemos/20cammar.pdf.

Cerveny, L. K.; Miller, A. \& Gende, S. (2020). Sustainable cruise tourism in marine world heritage sites. Sustainability, 12 (2), 611. https://doi. org/10.3390/su12020611

Cohen, E. (2005). Principales tendencias en el turismo contemporáneo. Política y Sociedad, 42 (1), 11-24. Recuperado de https://revistas.ucm.es/index.php/ POSO/issue/view/POSO050513.

Cohen, C.; Vereda, M. \& Benseny, G. (2019). Camarones y Puerto Deseado: Estudio de atractividad de dos puertos patagónicos para el desarrollo de turismo de cruceros. Revista Universitaria de Geografía, 28 (2), 57- 86. Recuperado de http://bibliotecadigital.uns. edu.ar/pdf/reuge/v28n2/v28n2a04.pdf

Coronato, A., Mazzoni, E., Vázquez, M. \& Coronato, F. (2017). Patagonia. Una síntesis de su Geografia Física. Universidad Nacional de la Patagonia Austral. Ediciones Universidad Nacional de la 
Patagonia Austral Recuperado de https://www.unpa. edu.ar/sites/default/files/publicaciones adjuntos/ PATAGONIA_una $\% 20$ sintesis $\% 20 \mathrm{de} \% 20$ su $\% 20$ geografia $\% 20$ fisica $\% 20$ web_0.pdf

Crouch, G. I. \& Ritchie, J. B. (1999). Tourism, competitiveness, and societal prosperity. Journal of business research, 44 (3), 137-152. https://doi. org/10.1016/S0148-2963(97)00196-3

Frere, E., Quintana, F. \& Gandini, P. (2005). Cormoranes de la costa patagónica: Estado poblacional, ecología y conservación. El Hornero, 20 (1), 3552. Recuperado de https://www.researchgate.net/ publication/262703778_Cormoranes_de_la_costa patagonica_Estado_poblacional_ecologia_y_ conservacion.

Garay Tamajón, L. A. \& Cànoves Valiente, G. (2012). Turismo de cruceros en Barcelona. De la marginalidad al liderazgo internacional. Boletín de la Asociación de Geógrafos Españoles, 60, 253-271. https://doi. org/10.21138/bage.1507.

Gil, M. N., Giarratano, E., Barros, V., Bortolus, A., Codignotto, J. O., Schenke, R. D., Góngora, G. M. E., Lovrich G., Monti, A. J., Pascual M., Rivas Andrés L.\& Tagliorette, A. (2019). Southern Argentina: the patagonian continental shelf. En World Seas: an Environmental Evaluation (pp. 783-811). Academic Press. https://doi.org/10.1016/B978-0-12-8050682.00040-1

González, R. C. \& Mendieta, M. D. (2009). Reflexiones sobre la conceptualización de la competitividad de destinos turísticos. Cuadernos de Turismo, 23 (23), 111-128. Recuperado de https://revistas.um.es/ turismo/article/view/70201.

Harrill, R. (2004). Residents' attitudes toward tourism development: a literature review with implications for tourism planning. Journal of Planning Literature, 18 (3), 251-266. https://doi. org/10.1177/0885412203260306

Instituto Nacional de Estadística y Censo de la República Argentina (INDEC) (2010). Censo 2010. Recuperado de https://www.indec.gob.ar/indec/web/Nivel4Tema-2-41-135

Jensen, M. \& Daverio, M. E. (2004). Los cruceros turísticos en Ushuaia, Argentina. Relaciones
Buque-Destino. Aportes y Transferencias, 1 (8). Recuperado de http://nulan.mdp.edu.ar/285/1/ Apo2004a8v1pp89-112.pdf

Johnson, D. (2002). Environmentally sustainable cruise tourism: a reality check. Marine Policy, 26 (4), 261270 https://doi.org/10.1016/S0308-597X(02)00008-8

Kottek, M., Grieser, J., Beck, C., Rudolf, B. \& Rubel, F. (2006). World Map of the Köppen-Geiger climate classification updated. Meteorologische Zeitschrift, 15(3), 259-263. https://doi.org/10.1127/09412948/2006/0130

Lefebvre, H. (2013). La producción del Espacio. Madrid: Capitán Swing. Recuperado de http://www. recolecta.net/buscador/single_page.jsp?id=oai:raco. cat:article/52729

Losano, P. \& Tagliorette, A. (septiembre 2012). El turismo de cruceros en la Ciudad de Puerto Madryn, Chubut, Patagonia Argentina [Trabajo Presentado]. $5^{\circ}$ Congreso Latinoamericano de Investigación Turística, Sao Paulo.

Mantero, J. C. (1999). Actividad turística y desarrollo local. En E. Amadasi (Ed.), Política turística argentina. Bases para su reformulación (pp. 63-92). Ladevi Ediciones.

Martínez, C. I. (2012). Perspectivas del turismo de cruceros en Argentina en el marco de las tendencias mundiales. Notas en Turismo y Economía, 4, 44-71. Recuperado de http://sedici.unlp.edu.ar/bitstream/ handle/10915/27079/Documento_completo. pdf? sequence $=1$ \&isAllowed=y

Martner Peyrelongue, C. (1999). El puerto y la vinculación entre lo local y lo global. EURE, 25 (75), 103-120. https://doi.org/10.4067/s025071611999007500005

Ministerio de Turismo de la Nación (MINTUR) (2016). Plan Federal Estratégico de turismo Sustentable. Recuperado de https://es.slideshare.net/david20/ plan-federal-de-turismo-sustentable-argentina-2016

Monfort Mir, V. M. (1999). Competitividad y factores críticos de éxito en los destinos turísticos mediterráneos Benidorm y Peñiscola [Tesis doctoral]. Universitat de Valencia, Valencia, España. Recuperado de http://www.cervantesvirtual.com/ 
obra/competitividad-y-factores-criticos-de-exito-enlos-destinos-turisticos-mediterraneos-benidorm-ypeniscola--0/

Morello, J., Matteucci, S. D., Rodriguez, A. F. \& Silva, M. E. (2012). Ecorregiones y complejos ecosistémicos argentinos (1 ed.). FADU.

Oslender, U. (2002). Espacio, lugar y movimientos sociales: Hacia una "Espacialidad de resistencia". Scripta Nova Revista Electrónica de Geografia y Ciencias Sociales, 6, 1-16. Recuperado de https:// dialnet.unirioja.es/servlet/articulo? codigo $=496883$

Otero, A. M. (9 - 11 de noviembre de 2000). Planificación y manejo de atractivos turísticos culturales [Documento de conferencia]. VI Seminario Internacional de Arquitectura Paisajista Patrimonio Paisajista: Turismo y Recreación. La Plata.

Paasi, A. (1986). The institutionalization of regions: a theoretical framework for understanding the emergence of regions and the constitution of regional identity. Fennia, 164, 105-146. Recuperado de https:// fennia.journal.fi/article/view/9052

Prats, L. (2005). Concepto y gestión del patrimonio local. Cuadernos de Antropología Social, 21, 17-35. Recuperado de https://www.redalyc.org/ pdf/1809/180913910002.pdf

Ritchie, J. R. B. \& Crouch, G. I. (2003). The competitive destination. A sustainable tourism perspective. Wallingford: CABI Publishing.

Roccatagliata, J. A. (2008) Argentina. Una visión actual y prospectiva desde la dimensión territorial. Buenos Aires: Emecé Editores.

Ruiz-Velazco Castañeda, A.H. (2015). La competitividad territorial y el potencial socioeconómico urbano. Revista Lider, 26 (33), 39-59. Recuperado de https:// dialnet.unirioja.es/servlet/articulo? codigo $=5737453$

Schinelli, D. \& Vacca, C. (2007). Hacia una transformación económica de la Patagonia Austral: La actividad turística en la nueva dinámica productiva y su impacto en el empleo. Revista de estudios regionales y mercado de trabajo, 3, 211-234. Recuperado de http://sedici.unlp.edu.ar/bitstream/ handle/10915/67943/Documento_completo.4344. pdf-des.pdf-PDFA.pdf? sequence=1\&isAllowed=y
Schlüter, R. (1996). Chubut. Turismo, hábitat y cultura. Chubut: Editorial de la Universidad Nacional de la Patagonia San Juan Bosco.

Silveira, M. L. (2011). Territorio y ciudadanía: reflexiones en tiempos de globalización. Uni-pluri/ versidad - Versión Digital, 11 (3), 1-23. Recuperado de https://revistas.udea.edu.co/index.php/unip/ article/view/11833

Troncoso, C. A. (2008). Creando un lugar turístico y patrimonial: Las transformaciones en la Quebrada de Humahuaca a partir de los procesos de construcción de atractividad turística y patrimonialización [Tesis doctoral]. Repositorio Institucional - Universidad Nacional de Buenos Aires, Buenos Aires, Argentina.

Varisco, C. (2008). Desarrollo turístico y desarrollo local: La competitividad de los destinos turísticos de sol y playa [Tesis de maestría]. Universidad Nacional de Mar del Plata, Mar del Plata, Argentina. Recuperado de http://nulan.mdp.edu.ar/550/1/ varisco_c.pdf

Varisco, C., Castellucci, D., González, M. G., Muñoz, M. J., Padilla, N., Campoliete, L. \& Benseny, G. (2014). El relevamiento turístico: de Cicatur a la planificación participativa. Associação Brasileira de Estudos do Trabalho; Revista Da Abet, 4 (3), 4554. Recuperado de https://dialnet.unirioja.es/servlet/ articulo? codigo $=5599532$

Vejsbjerg, L. (2013). La importancia científica en la selección de atractivos turísticos patrimoniales. Una visión desde la espacialidad social. Scripta Nova. Revista electrónica de Geografía y Ciencias Sociales, 17 (433), 1-13. Recuperado de https:// rid.unrn.edu.ar/bitstream/20.500.12049/2731/1/ La\%20importancia\%20cient\%c3\%adfica $\% 20$ en $\% 201$ a $\% 20$ selecci $\%$ c 3\%b3n $\% 20$ de $\% 20$ atractivos $\% 20$ tur \% c $3 \%$ adsticos $\% 20$ patrimoniales $\% 20$ una $\% 20$ visi $\%$ c $3 \%$ b3n $\% 20$ desde $\% 201 a \% 20$ espacialidad $\% 20$ social.pdf

Vera, J. F., López Palomenque, F., Marchena, M. J. \& Antón, S. (1997). Análisis territorial del turismo . Madrid: Ariel Geografía.

Vereda, M. (2004). El desarrollo de Ushuaia como puerta de entrada del turismo antártico. Tendencias y competitividad [Tesis de Maestría]. 
Sede Iberoamericana de la Rábida, repositorio institucional - Universidad Internacional de Andalucía, Andalucía, España.

Vereda, M. (7 - 9 de junio de 2007). Análisis de la relación de Ushuaia con el turismo Antártico desde su rol de puerta de entrada marítima. Una aproximación desde los indicadores socio-económicos para la temporada 2005/2006. [Documento en Actas]. VIII Jornadas Nacionales y II Simposio Internacional de Investigación - Acción en Turismo. Posadas, Argentina.

Vereda, M. (2008). Tierra del Fuego y Antártida. Un inventario de recursos turísticos desde la idea de complementariedad. Estudios y perspectivas en turismo, 17 (3), 199-225. Recuperado de https:// www.redalyc.org/pdf/1807/180713895001.pdf

Vereda, M. \& Jensen, M. (2014). La configuración del espacio turístico Tierra del Fuego, Antártida e Islas del Atlántico Sur. El rol de Ushuaia como puerta de entrada a la Antártida. (Proyecto de Investigación 197/2011) Ushuaia: Universidad Nacional de la Patagonia San Juan Bosco, Argentina.

Wallingre, N. (2017). Desarrollo del turismo en América Latina. Fases, enfoques e internalización. Quilmes: Universidad Virtual de Quilmes. 